\title{
A EVOLUÇÃO DAS POLÍTICAS DE ATENDIMENTO À INFÂNCIA NO BRASIL: ENTRE CONCESSÕES E 0 RECONHECIMENTO DE DIREITOS
}

\section{DEVELOPIMENTS IN ATTENDANCE POLICIES TO CHILDHOOD IN BRAZIL: BETWEEN CONCESSIONS AND RIGHTS RECOGNITION}

\section{Ione da Silva Cunha ${ }^{1}$}

Resumo: A trajetória do sentimento de infância passou por diversas fases até que o indivíduo compreendesse de maneira efetiva as diferenças entre vida adulta e infância, e essas alterações influenciaram os comportamentos posteriores. $\mathrm{O}$ sentimento de infância foi um conceito gradualmente construído nas consciências, bem como o conceito de família e de afetividade entre os seus integrantes. A realidade brasileira foi muito diferente da apresentada nos países europeus, e um dos problemas a ser considerado, é que entre nós, a escolarização e a emergência da vida privada chegaram com grande atraso se comparados ao que aconteceu em outros países ocidentais. Somente nos anos 80 do século XX, o Brasil começa a desenvolver uma legislação que reconheça e resguarde os direitos de crianças e adolescentes, demonstrando uma mudança no sentimento da sociedade em relação à infância.

Palavras-chave: Infância. Direitos. Políticas de atendimento.

\begin{abstract}
The feeling of childhood trajectory went through several stages until the individual understand effectively the differences between adulthood and childhood, and these changes have influenced subsequent behavior. The feeling of childhood was a concept gradually built in the consciousness and the concept of family and affection among its members. The Brazilian reality was very different from that in European countries, and one of the issues to be considered is that between us, the school and the emergence of private life came very late compared to what happened in other Western countries. Only in the 80s of the twentieth century, Brazil begins to develop legislation that recognizes and Safeguard the rights of children and adolescents, demonstrating a change in sentiment of society in thier childhood.
\end{abstract}

Keywords: Childhood. Rights. Attendance policies.

1. Pedagoga, Mestre e Doutora em Educação pela Universidade Estadual Paulista - UNESP. Professora Adjunta na Universidade Federal de Mato Grosso do Sul, campus de Três Lagoas. E-mail: ionescn@outlook.com 


\section{INTRODUÇ̧̃̃O}

Nos últimos tempos, em grande parte do mundo ocidental, a infância tem sido reconhecida como uma fase da vida que deve ser protegida da exposição inadequada a determinados assuntos ou acontecimentos, bem como resguardada de atitudes e situaçóes violentas. Ao mesmo tempo, nunca se falou tanto em violência contra a criança como na atualidade e diariamente somos alcançados por notícias divulgadas por todos os meios de comunicação. Essa realidade certamente não se refere a fato recente e sabemos que não deve ser vista como se nunca tivesse existido, porém, que sempre fora tratada de maneira velada, o que por muito tempo nos levou a crer que a criança fosse respeita$\mathrm{da}$, causando-nos espanto e revolta quando alguns casos de maus tratos, em sua maioria praticados no ambiente extrafamiliar, chegavam ao conhecimento público. Porém, nem sempre ao longo da história, o sentimento em relação à infância foi o mesmo. Ariès (1981) nos mostra que a trajetória do sentimento de infância desde a Idade Média passou por diversas fases até que o indivíduo compreendesse de maneira efetiva as diferenças entre a vida adulta e a infância, e essas alteraçóes influenciaram os comportamentos posteriores. O sentimento de infância foi um conceito gradualmente construído nas consciências, bem como o conceito de família e de afetividade entre os seus integrantes, e tal fato não poderia deixar de trazer consequências ao tratamento dado às crianças que por muito tempo foram consideradas como que pessoas menores, que merecessem menos atenção, ou que dela não precisassem por se encontrarem na mesma esfera em que os adultos.

Essa concepção, que aos poucos foi se modificando, dando lugar a um sentimento de atenção às necessidades individuais da infância, tanto físicas, quanto afetivas e emocionais, teve repercussóes diferentes nos diversos lugares por onde passou a ser implantada. No caso do Brasil, podemos dizer que veio carregada de muitas contradiçóes pertencentes às diversas fases de seu desenvolvimento e que devem ser consideradas na compreensão de um fato tão abrangente quanto o da concepção de infância e da compreensão dos direitos que lhe são inerentes.

A realidade brasileira foi muito diferente da apresentada nos países europeus, e um dos problemas a ser considerado, é que entre nós, a escolarização e a emergência da vida privada chegaram com grande atraso se comparados ao que aconteceu em outros países ocidentais. É preciso acrescentar à nossa análise, os problemas que vieram como herança dos colonizadores. No caso brasileiro, além das dificuldades que afligiram a criança europeia, tivemos outras, como por exemplo, os naufrágios nos tempos de colonização, que acentuaram o problema de separação entre pais e filhos e o da escravidão que representou grande atraso para o desenvolvimento do país e deixou muitas crianças à margem da sociedade. É importante lembrar que os escravos permaneciam sem identidade até os quatorze anos e no Brasil a escravidão só acabou no final do século XIX, mesmo assim, deixando diversas sequelas e dificuldades para a população negra de um modo geral, problema que alcançou diretamente as crianças. 


\section{A INFÂNCIA NO BRASIL E SUAS RAÍZES HISTÓRICAS}

Um dos problemas que acompanha o estudo da infância no Brasil é a falta de relatos sobre a trajetória das crianças, principalmente as pobres e negras e as poucas narrativas que foram deixadas a esse respeito não são provenientes nem daqueles que as experimentaram, nem de suas famílias, mas das instituiçôes oficiais, fato que pode levar a uma visão retorcida da realidade (DEL PRIORE, 2000; MARCÍLIO, 1998; VENÂNCIO, 1999; RIZZINI, 2007).

Uma dificuldade apontada pelos autores para se conseguir relatos sobre crianças se deve ao fato de que nesse tempo se crescia muito cedo. No Brasil já no século XVIII, as mulheres poderiam se casar desde os doze anos e com quinze já se considerava a população como adulta. Além disso, a História por muito tempo relatou os fatos do ponto de vista da população mais forte e dominante, e obviamente a criança não seria o ponto de partida para tais relatos.

Poderíamos começar a pensar a história da infância no Brasil a partir das crianças que foram trazidas no período de colonização, pois além de homens e mulheres, crianças também estavam presentes no povoamento realizado no século XVI. Ramos (2000) nos mostra que nas longas viagens marítimas, encontravam-se nos navios não apenas as crianças que vinham em companhia de seus pais, mas também outras tantas na condição de grumetes e pajens, conhecidas como "órfẫs do Rei”. As meninas eram enviadas ao Brasil, para se casarem com os súditos da coroa, os meninos, participavam da populaçáo dos navios como grumetes, ou seja, ajudantes de marujos. As crianças, de acordo com esse autor, eram consideradas como pouco mais que animais e imaginava-se que sua força de trabalho deveria ser aproveitada ao máximo.

Elas eram arregimentadas de diferentes modos. Havia as que eram vendidas por seus pais como "força de trabalho". Essas eram provenientes de famílias carentes que recebiam uma quantia para permitir que seus filhos fossem enviados às colônias tanto para trabalhar nos navios, quanto para servir como mão de obra na própria colônia. Havia também as meninas pobres, reunidas entre os orfanatos de Lisboa e Porto, a fim de serem enviadas, sobretudo à Índia, mas algumas acabaram vindo para cá (RAMOS, 2000).

Dentre os meninos recrutados para trabalhar, Ramos aponta que um dos métodos para esse recrutamento, era o rapto de crianças judias, que eram arrancadas à força de seus pais. Como essas famílias não precisavam do pagamento feito pela Coroa, fica descartada a possibilidade de venda de crianças, levando os historiadores a compreender que esse método cruel significava, simultaneamente, um meio de obter mão de obra e manter sob controle o crescimento da população judaica em Portugal.

De acordo com Ramos (2000), os grumetes eram selecionados entre os órfãos e famílias pobres, de onde se retiravam os meninos entre nove e dezesseis anos e muitas vezes até com menor idade. Até o início do século XVII cerca de dezoito por cento da tripulação era composta por esses grumetes, mais tarde, porém, chegou a cinquenta por cento da tripulação. Como se não bastasse 
toda a crueldade com que eram separadas de suas famílias, ou a falta de cuidado para com algumas delas, o longo caminho marítimo reservava a essas crianças surpresas nada agradáveis. Eram comuns abusos sexuais por parte dos marujos rudes e violentos, que atacavam até mesmo aquelas meninas que se encontravam em companhia de suas famílias.

Sofriam juntamente com os adultos a falta de uma alimentação adequada, pois ao longo do caminho parte dos alimentos se deteriorava e a água se tornava escassa. Os grumetes chegavam a se alimentar de ratos e eram obrigados a dormir no convés, a céu aberto, sujeitos à ação de sol e chuva. Eram também violentados por marujos inescrupulosos ou mesmo por oficiais, a quem muitos meninos se entregavam para se prostituir, como forma de obter proteção de um adulto. Um último infortúnio ainda as atingia: era o fato de correrem o risco de serem jogadas ao mar pela tripulação em caso de naufrágio para que se livrassem de peso.

Tem início assim, a história da criança brasileira não índia e pertencente à classe popular, a partir da colonização. Uma história nada fácil, que tem ao longo dos anos se repetido e que ainda no século XXI é protagonizada por um número expressivo de crianças sexualmente abusadas e exploradas, que sofrem maus tratos ou que são obrigadas a trabalhar para sobreviver e muitas vezes para ajudar no sustento da família.

Além dessas crianças que para cá foram trazidas e que heroicamente conseguiram sobreviver para chegar até aqui, em tempos de colonização, podemos pensar em outros tipos de crianças brasileiras. Teremos as que aqui nasceram, provenientes dos casamentos entre os próprios portugueses ou da união com indígenas e mais tarde com negros. Podemos pensar também na criança indígena que aqui foi encontrada e que foi alvo da educação e evangelização dos jesuítas e um pouco mais adiante, encontraremos a criança negra, filha de escravos e aquelas que eram fruto das relaçôes furtivas entre senhores e escravas.

Coincidentemente, este é também o momento da "descoberta da infância" na Europa, fato que segundo Del Priore (1995, p. 13), proporcionou aos jesuítas uma visão diferenciada a respeito dos pequenos indígenas a serem catequizados. Estes, juntamente com os órfẫos trazidos de Portugal para auxiliá-los, eram vistos como "pequenos-Jesus a pregar e a sacrificar-se entre as 'brenhas' e os 'sertôes', para a salvação e consequente adestramento moral e espiritual [...]”. Porém, o sentimento de valorização da criança não afastou o ensino dos jesuítas do zelo pela forte disciplina e as exigências características da Companhia de Jesus. Acreditava-se piamente que os "vícios e pecados deveriam ser combatidos com açoites e castigos."

Havia a preocupação dos jesuítas em evangelizar os índios e devido à dificuldade encontrada em fazê-lo com os adultos, passaram a cercar as crianças com seus cuidados e ensinamentos, na tentativa de alcançar não somente os filhos, mas também os pais. Algumas crianças, porém, eram entregues por estes aos padres para que fossem ensinadas. Os pequenos índios eram considerados como "folhas em branco" nas quais poderia se inscrever os ensinamentos considerados necessários para se acabar com alguns costumes locais e levá-los a um comportamento considerado cristão. 
Esse tipo de situação trouxe uma verdadeira mudança para a vida dessas crianças. Elas passaram a aprender ofícios e quando adultos muitos realmente viveram como cristáos, embora a maioria quando chegava à adolescência retornava às origens e voltava a viver segundo os seus costumes. Houve até mesmo a tentativa de enviar alguns dos jovens indígenas para a Europa para que prosseguissem nos estudos e entrassem para a Companhia de Jesus, porém, esses planos tiveram que ser modificados devido à proibição da própria Companhia em Portugal (DEL PRIORE, 2000).

Já a criança negra foi praticamente esquecida nos relatos. Os filhos dos escravos eram também escravos e, portanto, deveriam ser tratados como tais, não importando sua idade, o que implicava em nenhum direito à educação. Segundo Scarano (2000), o nascimento de uma criança escrava era visto com bons olhos somente porque representava a certeza de uma ama de leite para alimentar as crianças dos senhores. Em pouco tempo, as mães escravas tinham que voltar a trabalhar e deixavam seus bebês com idosos e outras crianças. Náo podemos nos esquecer que a moradia era a senzala, e esta se encontrava em condiçóes sub-humanas. As crianças que ali viviam passavam por situaçôes muito difíceis, enfrentando todo tipo de doenças e uma alimentação inadequada para a idade e pobre em termos nutricionais.

Uma questão importante apresentada por Del Priore (2000), em relação ao comportamento das famílias com seus filhos é que as mães na América recebiam forte influência das índias que costumavam amamentar seus filhos por muito tempo ao contrário das europeias, que conforme vimos, entregavam seus bebês às amas-de-leite. Por outro lado, devido à influência das mães negras, é introduzido o costume de se alimentar as crianças desde cedo com alimentos engrossados com farinha, o que trazia muitos problemas de saúde e deixavam os médicos em estado de alerta.

De acordo com a autora, a criança era a vítima preferida das crises existentes, tanto no que diz respeito às tensóes sociais, quanto às crises econômicas e até mesmo em relação às doenças e epidemias. As diferenças sociais acentuavam as distinçôes entre ricos e pobres e os últimos, sem dúvida, estavam mais vulneráveis e ficavam mais adoentados.

Os hábitos da época também atrapalhavam o desenvolvimento físico e a saúde das crianças. O costume de apertá-las com panos e as deixar abafadas, possibilitavam muitas vezes a morte desses pequenos. Muitas crendices levavam as pessoas a recorrerem a métodos com pouca comprovação científica e de baixa eficácia. Os remédios conhecidos e utilizados também não atendiam a todas as necessidades. Assim, a mortalidade infantil aqui também era muito alta.

Ao longo do século XVIII e inicio do XIX, houve um grande investimento no recrutamento infantil para trabalho nos navios. Venâncio (2000) aponta que, ao longo da Idade Moderna, crianças pobres, órfâs e rejeitadas eram recrutadas para trabalhar nos navios e servir nas guerras, isso acontecia quase que sem nenhuma preparação. Baseavam-se na ideia de que crianças órfãs, bastardas ou abandonadas se tornariam soldados ou marinheiros ideais, tendo a pátria como mãe e dedicariam à nação todo amor, fidelidade e lealdade que poderiam dedicar a seus familiares. 
Essas crianças eram recrutadas das casas de expostos, onde viviam até os sete anos, indo a partir desse momento, morar nas Companhias de Aprendizes Marinheiros. Havia, porém, aqueles provenientes de famílias pobres, que eram inscritos por seus próprios pais, que recebiam um pagamento para isso. Esse ato, apesar de parecer à primeira vista, falta de amor paterno, é descrito por Venâncio (2000) como uma atitude de preocupação e desvelo familiar, pois esta era uma das poucas alternativas de aprendizado profissional destinada à infância pobre. $\mathrm{O}$ autor nos mostra também que no século XIX a Companhia de Aprendizes Marinheiros foi uma das raras opçôes de ascensão social para os filhos de forros ou de negros livres.

A vida nos estaleiros, porém, era brutal. Nos alojamentos era possível presenciar bebedeiras, brigas e xingamentos e as crianças eram obrigadas a conviver com presos condenados a trabalhos forçados e com menores delinquentes. Por outro lado, esses meninos tinham que enfrentar os métodos truculentos utilizados pelos oficiais e guardas para manter a disciplina e ainda encontravam-se sujeitos a uma alimentaçáo baseada em farinha de mandioca e charque e, portanto, pobre em proteínas e outros nutrientes, facilitando a proliferação de anemias ou infecçôes como a tuberculose.

No entanto, é importante lembrar que nos cortiços onde esses meninos moravam, eles também estavam sujeitos à fome e aos maus-tratos. Apesar disso, Venâncio (2000) aponta que os administradores das companhias constantemente referiam-se em ofícios e relatórios, às fugas praticadas por diversos meninos. Essas fugas chegaram até mesmo à trinta por cento dos matriculados.

Um pouco mais tarde encontramos outra dificuldade vivenciada pelas crianças brasileiras. Essa se relaciona ao fato de terem sido fortemente utilizadas como mão-de-obra nas industrias. $\mathrm{O}$ processo de industrializaçáo que na Europa ocorreu em fins do século XVIII, aqui no Brasil teve força somente no início do século XX em grandes cidades como São Paulo e Rio de Janeiro. Do mesmo modo que lá, se contou com a utilização de todo tipo de mão de obra, principalmente a que pudesse representar economia, encontrando-se nesse meio a mão de obra infantil. As crianças contratadas para trabalhar nessas fábricas, muitas vezes tinham apenas oito anos de idade e só para lembrar alguns dos riscos que corriam, podemos falar sobre os ferimentos nas máquinas que poderiam trazer sequelas físicas irreversíveis ou morte prematura das crianças, bem como o perigo de choques elétricos.

Um grande problema que precisa ser apontado é o do exercício de funções impróprias para a idade, bem como a precariedade das instalaçôes, tornando a situação ainda mais grave para as crianças, sem falar no fato de que elas participavam da fabricaçáo de todo tipo de material como: bebidas, cigarros, charutos, vidros, metais, tijolos, etc.

As relaçóes de poder no trabalho castigavam ainda mais os pequenos. Além dos acidentes de trabalho, eles tinham que enfrentar os maus-tratos dos patrôes e chefes, que muitas vezes chegavam a lhes causar ferimentos. Esses se esqueciam que apesar de operárias, continuavam crianças e lhes exigiam um desempenho profissional de adultos. Moura apropriadamente nos mostra que apesar de viverem aquela situação, 
[...] o mundo do trabalho não subvertia a infância e a adolescência a ponto de excluir $\mathrm{o}$ lúdico de suas vidas. As brincadeiras dos menores teimosamente resistiam à racionalidade imposta pelo ambiente do trabalho e foram, ao longo do tempo, em nome da disciplina exigida nos regulamentos das fábricas e oficinas, o claro detonador de atitudes violentas (MOURA, 2000, p. 268).

Do mesmo modo que no período anterior, muitas dessas crianças viviam em cortiços e por isso também enfrentavam problemas de saúde devido às más condiçôes dos alojamentos e à alimentação precária. Porém, as fábricas exploravam as crianças de maneira cruel, ao lhes impor excessivas jornadas de trabalho, que chegavam a 14 horas por dia, impossibilitando-lhes inclusive a frequência à escola. Dentro dessas fabricas presenciava-se também um ambiente com má iluminação e arejamento precário, sendo esses fatores determinantes também para que ficassem expostas a doenças, encontrando-se extremamente vulneráveis às mesmas (MOURA, 2000; ROCHA, 1997).

Se não bastassem todos esses problemas, o salário das crianças também era mais baixo que o dos adultos e nem passava por suas mãos, pois era entregue diretamente a seus pais ou responsáveis. Sob a desculpa de retirá-las das ruas, muitas crianças e adolescentes que entravam para a marginalidade eram enviados a essas fábricas, chegando-se ao ponto de se justificar o emprego de crianças sob um claro regime de exploração de mão de obra, como realização de "filantropia".

O movimento operário militou rigidamente contra o trabalho infantil, talvez nem tanto por se preocupar com as crianças e adolescentes, mas sim porque, uma vez que estes ganhavam menos, acabavam retirando a oportunidade de trabalho de um adulto. De qualquer maneira, esse movimento e suas manifestaçóes foram muito importantes para alertar a opinião pública a respeito do assunto. Na mesma medida, outros personagens sociais importantes passaram a criticar e denunciar tal atitude, bem como, cobrar uma ação efetiva por parte do governo, como jornalistas, políticos e alunos de pós-graduação das faculdades de medicina, que acabaram conseguindo alguns avanços em relação ao assunto.

A história da população pobre do país apresenta um movimento crescente de problemas e dificuldades. A dureza da vida levou os pais a abandonarem cada vez mais seus filhos para que pudessem trabalhar, ou mesmo deixá-los por conta de instituiçóes apropriadas devido à impossibilidade de criá-los. Esse número cresceu assustadoramente e trouxe à tona uma nova ordem de prioridade no atendimento social ultrapassando o nível da filantropia privada e seus orfanatos, transformando-a em problema do Estado e necessitando de políticas sociais e legislação específica.

\section{HISTÓRICO DAS POLÍTICAS DE ATENDIMENTO À CRIANÇA NO BRASIL}

No Brasil as desigualdades já são uma forma de violência quase que insuperável. De um modo geral, em vários segmentos da sociedade, as dificuldades provenientes dessas diferenças fazem com que a população, principalmente a mais pobre, passe por situaçôes de abandono 
do poder público, miséria e insegurança. Isso tem acontecido com a sociedade como um todo e com a criança não seria diferente.

Todo o caminho percorrido na primeira parte desse texto nos ajuda a ter uma visão geral a respeito do tratamento dado à criança, especialmente à criança pobre no Brasil ao longo dos anos. Também Marcílio (1998) nos mostra que a história social da América Latina náo pode ser estudada de maneira dissociada da pobreza, da marginalidade social, da criança ilegítima e da criança abandonada. Por isso é preciso compreender quais foram as relaçóes da criança pobre e muitas vezes abandonada com a sociedade por um longo período da história brasileira.

Segundo Marcílio (1998), da mesma forma que na Europa, aqui também houve a fase caritativa que pode ser observada do período colonial até meados do século XIX. Nessa fase, todas as açóes em favor dos pobres eram vistas como meios de conseguir a piedade de Deus para si mesmo. É nesse período que surgem as primeiras instituiçôes de proteçâo à criança órfã ou abandonada. Surgem as primeiras rodas de expostos e com elas, instituiçóes de atendimento às crianças, as misericórdias.

É importante, porém, frisar que quem trouxe a prática de abandonar os filhos para as Américas foram os brancos. Espanhóis e Portugueses passaram a realizar aqui os atos de exposição das crianças conforme era comum na Europa. A situação de miséria, exploração e marginalização levou os indígenas e depois os africanos e os mestiços a seguir o exemplo.

$\mathrm{O}$ assistencialismo da fase caritativa tem como característica principal, o sentimento de fraternidade humana, de conteúdo paternalista sem pretensão de mudanças sociais. Foi um movimento religioso que privilegiou a caridade e a beneficência em sua atuação. A partir de uma concessão da Coroa, as Câmaras Municipais firmaram convênios com as Santas Casas de Misericórdia que estabeleceram Rodas e Casas de Expostos já comuns na Europa.

O Estado absolutista português não atentava para a assistência social, uma vez que estava preocupado com a preservação dos interesses das classes privilegiadas. Aos poucos, porém, foi se compreendendo que o Estado teria a responsabilidade pela administração dos negócios públicos, ou seja, pela economia em geral, e a assistência seria responsabilidade da piedade particular e de associações leigas (VENANCIO, 1999; RIZZINI, 2007).

No passado não se usava o termo abandonado, mas sim enjeitado ou exposto. Durante os séculos XVIII e XIX, milhares de crianças foram enviadas a instituiçôes assistenciais existentes nas cidades brasileiras. Esses abrigos nas Santas Casas de Misericórdia eram destinados a receber recémnascidos abandonados por suas famílias.

Também aqui as famílias das camadas populares não viam os recursos à assistência como uma demonstração de ausência de amor pela criança, pelo contrário, a procura pelas instituiçóes 
quase sempre era decorrência de extrema pobreza e tinha por objetivo proteger as crianças do infanticídio (VENÂNCIO, 1999; MARCÍLIO 1998).

As casas da Roda não eram asilos. As crianças ali deixadas, num primeiro momento eram cuidadas por amas-de-leite que amamentavam os bebês em troca de pagamento, em seguida essas crianças eram enviadas a famílias que recebiam ajuda financeira para cuidar delas. Porém, de acordo com Marcílio (1998, p. 237), a maioria das crianças nas Rodas falecia antes de completar um ano e "de todas as categorias que formaram a população brasileira, incluindo os escravos, a dos expostos foi a que apresentou os maiores índices de mortalidade infantil, até o fim do século XIX.”

Por outro lado, Rizzini (2007) aponta que na passagem do regime monárquico para o republicano, a infância foi revestida de significado especial. Ela simbolizava a esperança e deveria ser vista como um valoroso patrimônio da nação, um ser em formação, que tanto poderia ser transformado em "pessoa de bem", quanto em uma pessoa degenerada. Assim, zelar pela criança deixa de ter apenas o sentido de caridade para significar a garantia da ordem ou da paz social.

Desse modo, acreditava-se que se a criança fosse adequadamente educada, poderia ser útil à sociedade. Ao mesmo tempo, porém, em que era vista como esperança, também poderia representar uma ameaça para a sociedade, por isso deveria ser afastada dos vícios e da criminalidade, principalmente nas ruas e casas de detenção e desse modo, até o final do século XIX, cuidar da criança e vigiar sua formação moral, representava salvar a nação. Nesse momento, passa a haver uma maior cobrança da família que ao se mostrar incapaz ou indigna na criação dos filhos poderia perder a guarda dos mesmos que passariam à responsabilidade do Estado.

É importante frisar, que em meados do século XIX, as instituiçóes coloniais de proteção à criança desvalida não respondiam mais às necessidades decorrentes da nova realidade. Tem inicio assim, até meados do século XX, devido às diversas transformaçóes sociais em relação à criança desvalida, a fase descrita por Marcílio (1998) como fase filantrópica de atendimento à criança no Brasil. A filantropia surge não mais com a preocupação de simplesmente salvar a alma, mas sim o corpo da criança. Tinha como objetivo intervir no trabalho das misericórdias, procurando transformá-las em institutos de proteção à infância abandonada a serviço do poder público. A proposta era de criação de instituiçôes que deveriam oferecer instrução elementar, formação cívica e capacitação profissional das crianças desvalidas. A ideia era de tirar a criança da ociosidade dos asilos.

Das transformaçōes ocorridas na sociedade brasileira entre os séculos XIX e XX, verifica-se que a mais importante foi o fim da escravidão. Porém, o desenvolvimento da sociedade brasileira também contribuiu para que outras mudanças ocorressem, e elas podem ser apontadas pelos seguintes acontecimentos: o controle da mortalidade infantil, a ascensão da mulher na sociedade, modernização do país como um todo, aumento no número de escolas públicas e privadas e criação de Universidades e Institutos de Pesquisa. 
Porém, como todo processo de modernização, este também, possui um lado que pode ser perverso, que é o crescimento demográfico. Um rápido movimento de urbanização e a crescente construção de indústrias, produz o aumento da pobreza e de habitaçóes precárias, passando a haver cada vez mais favelas e cortiços nas grandes cidades. Além disso, se acentua a exploração de mãode-obra urbana e despreparada, oferecendo uma remuneração baixa, priorizando o trabalho de mulheres e crianças.

Como a história de ambos está interligada, devido à forte relação mãe e filho, para compreender os problemas que atingiram a criança, devemos entender os diversos problemas que a migração para as cidades trouxeram para a mulher. A dificuldade de identificação com o contexto cultural e a falta de apoio e controle familiar, fizeram com que ela ficasse à mercê da exploração. Sem preparo, lhe restavam poucas opçóes de emprego como o trabalho nas fábricas com baixa remuneração, ou nas casas de família como doméstica ou ainda nas casas de prostituição. Muitas dessas mulheres acabaram se tornando mães solteiras, o que ajudou a aumentar as estatísticas de bebês abandonados.

Nesse contexto as crianças eram as que mais sofriam, as que não eram abandonadas nas rodas, andavam maltrapilhas e desamparadas sem ter destino certo. Teve início a chamada "questão do menor", uma vez que a criança abandonada nas ruas poderia representar um constante perigo para a sociedade, pois estava sujeita à delinquência e aos vícios, havendo, portanto, à exigência de políticas públicas renovadas (MARCÍLIO, 1998; RIZZINI, 2007).

Merisse (1997) aponta uma nova fase de atendimento à criança no Brasil com início em meados do século XIX como fase higienista. Nesse momento, foram realizadas várias descobertas científicas relacionadas à infância e à saúde que vieram a alterar diversos setores da sociedade. Do fim do século XIX ao início do século XX foi realizado um grande debate sobre a Roda de Expostos. Médicos higienistas e juristas defenderam o fim das rodas, mostrando de diversas maneiras que essas eram danosas à infância. Ambos trouxeram propostas de política assistencial com base em novas técnicas científicas. Criticavam a velha assistência caritativa e davam ênfase à cientificidade da filantropia.

De acordo com Marcílio (1998), os médicos tinham a preocupação de combater a mortalidade infantil e para isso propunham um maior cuidado com o corpo, sua proposta era essencialmente preventiva. Os juristas ao se preocuparem com a infância desvalida e delinquente, buscavam teorias e soluçóes no exterior. Da escola de Milão, trouxeram a ideia de que uma educaçáo rígida era necessária para refrear a tendência natural ao crime. Das ideias positivistas de Augusto Comte (Ordem e Progresso), a tese de que a separação da infância problemática, desvalida, delinquente em grandes instituiçóes de regeneração e correção dos defeitos, era essencial, antes de devolvê-la ao convívio da sociedade estabelecida.

Esses pensamentos exerceram forte influência sobre aqueles que seriam os responsáveis pelas instituições de atendimento à criança. Por outro lado, passa a haver uma mudança no termo 
de designação e "criança”" começa a ser usado para os filhos de famílias bem estruturadas. Àqueles que são vítimas de uma infância desfavorecida, delinquente, carente, abandonada, é atribuída outra forma de tratamento, passando a ser chamados de "menor". A infância pobre não tinha acesso à cidadania, que nesse momento, seria assegurada pelo nascimento em uma família capaz de seguir os parâmetros de moralidade estabelecidos. Caso a família se mostrasse incapaz de fazê-lo perderia a guarda dos filhos. Por outro lado, a criança realmente abandonada, sem família, deveria ser diretamente tutelada pelo Estado (RIZZINI, 2007; LODOÑO, 1995).

A princípio, a grande preocupação da classe dominante foi em dar a essas crianças um atendimento que lhes proporcionasse uma educação suficiente para ocupar o lugar dos escravos. E a composição da força de trabalho pelos órfãos e desvalidos, foi marcante, pois eles estiveram presentes na abertura das primeiras rodovias, no alargamento dos portos e nos primeiros ofícios de manufatureiros (MARCILIO, 1998; MORAES, 2000).

A primeira mudança na política social de assistência ocorreu em 1855. Foi como que um Primeiro Programa Nacional de Políticas Públicas voltado para a criança desvalida. Surgiram os asilos em muitas províncias e deu-se prioridade à intensificação da instrução à criança desvalida para prepará-la para o trabalho e para bem servir. Assim, a filantropia atraía as elites por imaginarem que esta lhes permitiria exercer um melhor controle sobre a sociedade. E segundo Marcílio (1998, p. 207), "a filantropia tinha por escopo, preparar o homem higiênico, formar o bom trabalhador, estruturar o cidadão normatizado e disciplinado.”

A partir desse momento, tem inicio a preocupação com a separação entre instituiçôes. Não se poderia agrupar na mesma casa crianças abandonadas e crianças delinquentes. A proposta da filantropia era assistir para prevenir. Não sendo possível, entrava em ação a correção, que seria exercida pela repressão rigorosa, auxiliada pela polícia.

Nesse sentido, diversas instituiçóes foram sendo implantadas por todo o país. Muitas delas com o nome de "Casas de Artífices", pois tinham claramente o objetivo de ensinar um ofício. Nessas instituiçóes, geralmente criadas para meninos, era-lhes proporcionado acesso às primeiras letras e iniciação à aritmética, porém, o principal objetivo era de lhes proporcionar o aprendizado de diversos ofícios que os levasse a ingressar no mundo do trabalho de maneira mais efetiva. As meninas eram enviadas para instituiçóes, que embora mantidas pelo Estado, muitas vezes eram cuidadas por ordens religiosas, o que trazia para tais instituiçóes uma função extremamente moralizadora. $\mathrm{O}$ aprendizado dessas meninas em tais lugares, lhes proporcionava não apenas iniciação em leitura, escrita e aritmética, mas também o aprendizado de prendas domésticas e trabalhos manuais.

Ao contrário, porém, do que aconteceu com os meninos internos em estabelecimentos privados, as esferas governamentais não cogitaram utilizar essas meninas em atividades industriais, mas sim aproveitar as mais aptas à profissão no ensino de primeiras letras, uma vez que a procura pela profissão se tornou escassa em determinado momento (MORAES, 2000; MARCÍLIO, 1998). 
Assim, percebe-se nas instituiçóes femininas um caráter fortemente moralista e nas instituiçôes masculinas um regime disciplinar semelhante ao militar que Marcílio define da seguinte maneira:

Segundo princípios higiênicos e disciplinares, médicos e juristas criaram um verdadeiro projeto de prisão-modelo para menores carentes ou infratores, de acordo com os valores e as normas científicas propostas pelo filantropismo, segundo os quais, os meios fundamentais de recuperação eram a educação, o trabalho e a disciplina (MARCÍlIO, 1998, p. 218).

As crianças e adolescentes não eram vistos como tais, mas sim como perigos para a sociedade, por isso, a princípio as leis eram tão duras com eles. De acordo com a autora, o Código Criminal do Império de 1830 estabelecia como menoridade penal a idade de quatorze anos, o que demonstra uma visão distorcida a respeito da adolescência. A situação para a criança e o adolescente piorou ainda mais com o Código Criminal da República de 1890, pois nele a menoridade penal foi reduzida para os nove anos de idade.

Não se oferecia, porém, a segurança e tranquilidade necessárias a uma sobrevivência serena. Os que estavam abandonados e sozinhos tinham que trabalhar para sobreviver e além do trabalho nas indústrias, poderiam ser encontradas também nas ruas vendendo doces e jornais, ou ainda exercendo atividades de mensageiros, entregadores de encomendas, carregadores de feira, cambistas de loteria ou engraxates, muitos trabalhando em duas ou mais dessas atividades ao mesmo tempo.

Principalmente as crianças, tinham contra si a desvantagem física tendo constantemente que se sujeitar aos adultos, fora isso, viviam sob constante incerteza de alimentação e presenciavam todo tipo de promiscuidade, à qual também se encontravam expostas, correndo o risco de sofrer suas consequências estando sujeitos a toda sorte de moléstias e enfermidades (MORAES, 2000).

As críticas à situação de vida das crianças (sem escola, com trabalho não regulamentado ou com regulamentos desrespeitados e habitando em condiçóes desumanas) abriram a possibilidade de reivindicação de políticas de direitos e contestação às desigualdades. Sob a influência da "Declaração dos direitos da criança” de 1923, também conhecida como "Declaração de Genebra", foi criado no Brasil em 1924 o Juízo Privativo dos menores abandonados e delinquentes que pode ser considerado como um primeiro passo no sentido de reconhecimento da criança e do adolescente como sujeitos de direitos, embora ainda muito tivesse que ser feito (PASSETI, 2000).

Porém, ao pesquisar sobre o desenvolvimento do atendimento à criança abandonada e infratora no século XX, percebemos que o Estado deu prioridade às políticas de internação, escolhendo também assim, educar pelo medo. Essas instituiçôes nunca funcionaram, mas desde o primeiro código de menores de 1927, instituído pelo Decreto $\mathrm{n}^{\circ}$ 17.343/A, observamos um Estado que responde às exigências com internação, e que apesar de se responsabilizar pela situação de abandono das crianças e adolescentes, aplica-se a trabalhar com disciplina severa para acabar com 
o comportamento delinquente. $\mathrm{O}$ mais grave de tudo é que a criança pobre era considerada de antemão, como potencialmente perigosa, devendo ser atendida pelo Estado e rigorosamente acompanhada (MERISSE, 1997; MARCÍLIO, 1998; PASSETTI, 2000; RIZZINI, 2007).

Percebemos, portanto, que a criança além de ter seus direitos de ser humano e sua individualidade violadas, foi culpabilizada por isso, implicando tal medida em que fosse ela facilmente marginalizada. Não recebendo tratamento adequado nas instituiçóes para onde era enviada, permanecia cada vez mais distante da possibilidade de modificar o futuro que a aguardava.

O novo código estabelecia como menoridade penal a idade de dezoito anos e é possível reconhecer nele os primeiros passos em direção à proteção da criança. Porém, o documento identifica os infratores com a periculosidade a ser contida. O infrator era considerado "menor perigoso" e deveria ser mantido em estabelecimento adequado até que o juiz declarasse a cessação da periculosidade. Percebe-se então que o atendimento social transforma-se também em serviço penitenciário.

Como as exigências de uma educação para todos, eram cada vez mais acentuadas, o governo percebeu a necessidade de garantir o acesso dos pobres às escolas. Em São Paulo, uma lei estadual permitia que os alunos reconhecidamente pobres, mas que se destacavam nos estudos e em comportamento, fossem matriculados em escolas subvencionadas. O detalhe de exigir "bom" comportamento fazia com que aqueles que náo se enquadrassem nos modelos vigentes fossem marginalizados, pois eram não somente impedidos de frequentar tais escolas, mas encaminhados a instituições corretivas de comportamento. Assim, as escolas públicas e privadas deveriam atender crianças disciplinadas, já as crianças abandonadas e infratoras seriam atendidas em internatos e instituições próprias.

De acordo com Merisse (1997), somente em 1930, o Estado assume oficialmente suas responsabilidades na esfera de atendimento à infância com a criação do Ministério da Educação e Saúde. Antes disso, todas as açôes foram isoladas, apresentando-se em alguns lugares e não em outros.

O Decreto-lei n ${ }^{\circ} 2848$ de 1940 determina a inimputabilidade penal ao menor de dezoito anos. De acordo com esse decreto, o menor em situação diferenciada não é mais mencionado como "desvalido" ou "delinquente", mas como "perigoso". A política do Estado Novo, por ser extremamente paternalista, criou mecanismos de atendimentos aos menores que podem ser enquadrados como paternalismo assistencial. Nesse sentido, os Estados criaram órgãos de atendimento ao menor que visavam orientar e sistematizar os serviços de assistência a menores desvalidos e delinquentes. Seu objetivo era reprimir qualquer ação que pudesse ser considerada perigosa por parte desses jovens.

No início dos anos 40 são criados dois órgãos que irão atuar na área da infância. O primeiro foi o Departamento Nacional da Criança (DNCr), com o objetivo de atender a infância, a maternidade e a adolescência, fornecendo orientaçôes técnicas, repassando recursos aos Estados e entidades privadas e atuando como órgão fiscalizador. 
O segundo órgão foi criado em 1941, seguindo a lógica do sistema penitenciário de assistencialismo e punição, foi o SAM - Serviço de Assistência a Menores. Seguindo a política do Estado Novo de assistencialismo, paternalismo, autoritarismo e clientelismo, dava esse tipo de atendimento à criança e ao adolescente. $\mathrm{O}$ "menor" era visto acima de tudo como uma ameaça à sociedade que devia ser controlada a todo custo.

A partir de 1964 surgiram os programas interdisciplinares de reeducaçáo inaugurados com a Política Nacional de Bem-estar do Menor (PNBM). Esses, de acordo com os discursos, pretendiam modificar a fase repressiva, transformando-a em educativa, porém o menor continuou sendo visto como carente e abandonado e atendido pela filosofia e práticas carcerárias.

A lei 4513 de $1^{\circ}$ de dezembro de 1964 extinguia o SAM e propunha sua modernizaçáo como FUNABEM (Fundação Nacional do Bem-estar do Menor). A ela caberia formular e implantar a Política Nacional de Bem-estar do Menor em cada Estado, integrando-se a programas nacionais de desenvolvimento econômico e social. Passeti, (1995) mostra que o "problema do menor" era considerado a partir dos objetivos nacionais permanentes. Desse modo, não se pensava na criança e no adolescente como cidadãos possuidores de direitos, mas em indivíduos que deveriam se submeter às metas de desenvolvimento nacional.

O governo autoritário, "pensava" o povo brasileiro a partir de uma base teórica fundamentada na percepção harmônica da sociedade, a visão era a de um povo "tomado, constatado e reconstruído para uma meta futura de criação das condições de uma democracia de cunho liberal" (PASSETTI, 1995, p. 152).

Assim, de acordo com esse tipo de pensamento, o menor marginalizado teria como causa maior de sua situação, a desorganização da família, por isso ela era defendida como a única solução para se chegar ao patamar do bem-estar. Qualquer crítica que não apoiasse os fundamentos da concepção oficial seria considerada antipatriótica. Os pais eram considerados incapazes de cuidar de seus filhos, passando toda a responsabilidade para o Estado.

Acima de tudo, se pensava em oferecer à criança considerada carente, uma educação compensatória, pois se imaginava que essa suposta carência, conduziria a uma inaptidão generalizada, tanto linguística, quanto motora ou social. De acordo com esse pensamento o menor carente era incapaz da assimilar os ensinamentos e as informaçôes transmitidas, por isso precisaria de um atendimento educacional diferenciado. Não no sentido de educá-lo para a libertação dessa situação, mas sim de compensação moral.

Segundo Passetti (2000), em 1979, a implantação de um novo Código de Menores atualizou a PNBM formalizando a concepção "biopsicossocial" do abandono e da infração e explicitou a estigmatização das crianças pobres como "menores" e "delinquentes em potencial". Esse sentimento se expressa no artigo $2^{\circ}$ do referido código através da noção de "situação irregular": 
[...] para os efeitos deste código, considera-se em situação irregular, o menor: I- privado de condiçôes essenciais à sua subsistência, saúde instrução obrigatória, ainda que eventualmente em razão de a) falta, ação ou omissão dos pais ou responsável por provê-las. b) manifesta impossibilidade dos pais ou responsável por provê-las. II- vítimas de maus-tratos ou castigos imoderados impostos pelos pais ou responsáveis. b) manifesta impossibilidade dos pais ou responsável por provê-las (PASSETI, 2000, p. 370).

Percebe-se que o jovem, não necessariamente infrator, mais uma vez era culpabilizado pela situação de pobreza ou abandono que vivenciava. Esse era o cuidado do Estado com o adolescente que já não possuía muita coisa, mantê-lo sob vigilância para que não corresse o risco de se tornar delinquente, como se, nesses casos, isso fosse líquido e certo. Porém, esse Estatuto traz a ideia de que a FUNABEM deveria atender a todas as crianças e não somente às desajustadas. É criada a figura do Juiz de Menores e regulamentado o processo de adoção. Mais uma vez se chega à conclusão de que pela família os desajustes poderão ser superados.

Nos anos 80 , com o início da abertura política, temos também a busca por novas soluçôes para o tratamento das crianças e adolescentes, surge a necessidade de uma revisão imediata do código. A Constituição Federal de 1988 traz o fim da estigmatização formal da pobreza e sua ligação com a delinquência. Tem início um momento de discussão sobre o Estatuto da Criança e do Adolescente que traz uma outra visão sobre a infância. É finalmente abandonado o uso do termo "menor" que traz consigo tantos preconceitos e interdiçóes e se passa a falar em criança e adolescente. A criança abandonada passa a não ser mais atendida pela FUNABEM (Fundação Nacional de Bem-estar do Menor), mas por programas descentralizados de atendimento.

Surge um novo momento da filantropia no país, pois cria-se um vínculo entre Estado e organizaçôes não governamentais. O próprio Estatuto da Criança e do Adolescente redimensiona o papel do Estado, apresentando-o como o de orientar e supervisionar as açôes, reduzindo sua atuação na esfera de atendimento. É a partir daí que se facilita o aparecimento de ONGs. Essa nova filantropia é um meio de contençấo de custos do Estado e uma forma de gerar empregos no ambiente privado. De acordo com Passetti (2000), o empresariado passa a fazer filantropia, graças ao que deixa de pagar para o Estado.

Percebemos nesta caminhada pela história da criança e do adolescente e da formação de um vínculo da sociedade em relaçáo a eles, que nem sempre foram percebidos como indivíduos possuidores de direitos. Sofreram todo tipo de discriminação e maus tratos, se é que devemos deixar o verbo no passado e passaram por diversas incompreensóes ao longo do tempo.

Hoje vivemos um estágio de controle de emoçóes e pulsóes diferente da Idade Média e Elias nos mostra que nossa sociedade ainda assim, impóe às crianças e adolescentes níveis de controle que muitas vezes os próprios adultos não conseguem alcançar. Esses níveis, porém, são exigidos dos 
pequenos sem levar em consideraçáo a diferença existente entre infância e vida adulta. As crianças e adolescentes muitas vezes são realmente marginalizados por não atenderem aos padróes impostos por essa sociedade, mas isso não acontece por uma escolha sua, mas sim por força da situação social em que se encontram.

É difícil pensarmos que os direitos das crianças serão facilmente respeitados em um país que foi o último a abolir realmente a roda dos expostos de sua realidade, sendo que a última ainda existiu até os anos 50 do século XX. Por isso, pode-se dizer que muito ainda será preciso fazer em relação à criança e ao adolescente em nosso país para que a violência contra eles diminua e para que seus direitos de cidadáos e indivíduos sejam respeitados. Um dos primeiros direitos reconhecidos internacionalmente é o direito à educação.

\section{INFÂNCIA E DIREITO À EDUCAÇÃO}

Após duas Guerras nas quais a humanidade viu o respeito às individualidades e diferenças ser violado, principalmente na 2a Grande Guerra, as Naçóes consideraram da mais alta importância a publicação de uma Declaração Universal dos Direitos Humanos, que apesar de relatar o que deveria fazer parte das relaçóes humanas tanto dentro de um país, quanto de naçóes para naçóes, foi de extrema importância para que os direitos básicos dos indivíduos fossem respeitados.

A Declaração foi proclamada em dezembro de 1948 logo após o fim da Segunda Guerra Mundial, na tentativa de afirmar que os interesses das naçôes não podem se sobrepor aos interesses dos cidadãos e ao direito à vida e dignidade humana. Foi uma tentativa de proteger a humanidade do próprio homem e fazer com que as relações fossem, de alguma forma, repensadas.

Marcílio (sd) nos apresenta a ideia de que o século XX foi o século da criança, pois foi em seu desenrolar que houve a descoberta, valorização, defesa e proteção da criança, pensando-se em seus direitos básicos, reconhecendo-se que ela é um ser humano com características próprias e necessidades diferentes dos adultos.

Ao longo de todo o século, os direitos humanos foram cada vez mais sendo amplamente discutidos, especialmente após a $2^{\text {a }}$ guerra e seus horrores. Juntamente com o reconhecimento dos direitos de homens e mulheres à dignidade e respeito também as crianças passaram a ter seu espaço. É criado o UNICEF (Fundo Internacional de Ajuda Emergencial à Criança Necessitada - United Nations International Child Emergency Fund), que embora tivesse num primeiro momento o objetivo de atender às crianças órfãs da guerra, se tornou um órgão internacional em defesa dos direitos da criança. Em 1959 com a "Declaração Universal dos Direitos da Criança”, a ONU conseguiu impactar cada nação diante da necessidade de se proteger cada vez mais a infância. A criança passa a ser vista como um sujeito de direitos e como prioridade absoluta, o que pode ser considerado uma verdadeira revolução. Em 1989 foi realizada a "Convenção das Naçóes Unidas sobre os Direitos 
das Crianças" e até fins de 1996, noventa e seis por cento dos países já havia ratificado os termos da convenção, dentre eles o Brasil, que o fez logo em 1989. (MARCÍlLIO, sd)

A Declaração Universal dos Direitos Humanos no parágrafo $1^{\circ}$ do artigo 26 afirma:

Toda pessoa tem direito à educação. A educação deve ser gratuita, pelo menos no que se refere à instrução elementar e fundamental. A instrução elementar será obrigatória. A instrução técnica e profissional deverá ser generalizada; o acesso aos estudos superiores se dará para todos em plena igualdade e em função dos respectivos méritos.

Mas no Brasil a educação como direito só seria realidade a partir da segunda metade da década de 80 do século XX, no período de transição democrática. Para compreendermos como se deu esse processo de envolvimento com uma educação obrigatória e integradora, iremos retomar as relaçôes entre elite política, massa popular e educação no Brasil desde o século XIX.

Ainda no século XIX a educação foi vista como possibilidade de mudança na sociedade brasileira, porém as autoridades relutaram em reconhecê-la como tal e em democratizar o acesso do povo a ela. Isso ocorreu por questóes as mais variadas, fato que nos leva a pensar o quanto as políticas de exclusão têm sido realidade em nosso país há bastante tempo.

Essas políticas por si mesmas já podem ser consideradas uma violência contra o povo, essencialmente o mais pobre, que por meio de tais atitudes vê perpetuada sua impossibilidade de acesso aos mais diversos direitos. Nesse sentido, Rezende (2005) nos mostra que em 1822 muitos tentavam impedir que a abertura política viesse a acontecer no sentido de atender às demandas do povo, e com isso perpetravam a condenação da maioria ao analfabetismo, à fome e ao abandono. A autora aponta ainda que até 1920 a maneira como os dirigentes, em suas administraçóes públicas operavam, era fundada no descaso para com os interesses coletivos, tendo como objetivo real, a manutenção do povo no analfabetismo e, portanto, na exclusão da vida política.

Ao fazer uma análise de textos de grandes escritores da época, Rezende nos mostra que a educação voltada apenas para alguns, e a produção econômica visando o enriquecimento predador, ou seja, buscando a exploraçáo da terra e do homem, levando a um consumo supérfluo, voltado para o luxo e para uma concentração de riquezas responsável pela manutenção das desigualdades, formava a "base de um padrão de organização que se reproduziria numa lógica reforçadora da destruição - e não da construção - das potencialidades sociais e políticas da maioria dos brasileiros.” (REZENDE, 2005, p.53)

A autora também nos mostra que havia nesse momento um pensamento a respeito do povo brasileiro que o descrevia como violento, preguiçoso, alegre, triste, incapaz, imprevidente, desordeiro, etc. Essas explicações levavam em consideração a ideia de que tais características estavam relacionadas à natureza imutável do brasileiro como consequência do fato de que as forças 
naturais (biológicas, climáticas, étnicas) eram superiores e seriam capazes de determinar as sociais. Sendo assim, alguns pensadores da época no país consideravam desnecessário modificar a situação de exclusão e privação do povo brasileiro e o investimento nas instituiçôes sociais e políticas com vistas à sua alteração, seria desnecessário e inócuo, uma vez que o povo brasileiro possuía um modo de ser imutável.

Ao analisar as ideias de Fernando de Azevedo, a autora nos mostra que este foi um pensador que lutou para modificar tal concepção. Em primeiro lugar, refutou a tese de que a dificuldade de aprendizado e o desânimo eram consequência da mestiçagem ocorrida no país. Para tanto, passou a argumentar que o modo de ser era consequência das condiçôes sociais e não étnicas e se houvesse a pretensáo de se modificar o país, seria necessário alterar completamente as primeiras e reverter todo o sentimento de individualismo e clientelismo existente. Para Fernando de Azevedo, a educação seria a possibilidade de modificação das mentalidades, visando construir uma sociedade que vivesse em torno de interesses coletivos e democráticos. A reforma educacional, portanto, era vista por ele como a base para todas as demais reformas que a sociedade precisava empreender.

Esse pensamento de que a educação seria o primeiro caminho no sentido de trazer mudanças ao país não esteve presente somente nas obras de Fernando de Azevedo. Mesmo as elites intelectuais percebiam o quanto o país se distanciava de outros considerados, por elas, como "civilizados" devido ao alto índice de analfabetismo, que tinha como consequência o aumento da pobreza e do grau de miserabilidade.

Segundo as concepçóes de Rizzini (2007, p. 54), o povo não conseguia alcançar os níveis de educação necessários porque os velhos coronéis, "que governavam o país como governavam suas fazendas" não estavam nem um pouco interessados em oferecer-lhe educação, o que fazia com que continuasse dependente do benefício exclusivo de tais administradores, continuasse exposto à manipulação e exploração, fato que representava humilhação e vergonha para o Brasil diante do mundo.

A autora nos mostra também que o que caracterizava uma nação como civilizada era o senso de liberdade e de responsabilidade perante a pátria, o que levaria a excluir todos os países que se utilizassem da escravidão desse tipo de descrição. O Brasil estaria, portanto, muito distante de tal condição. Não apenas por causa da escravidão que esteve presente na história brasileira por tanto tempo, mas também porque a pobreza alcançava grande parte da populaçáo brasileira e ela era vista como algo humilhante para a nação, sendo assim, minimizar a pobreza, consistia em um teste de civilização, conforme o pensamento da época.

Se usarmos como exemplo, um país que conquistou a reputação de "altamente civilizado" deveremos atentar para as ideias implantadas na Inglaterra, com vistas a desenvolver políticas no sentido de minimizar tal problema. As primeiras açóes nesse sentido naquele país datam do início do século XVII, o que os levou no século XIX apenas a consertar alguns pontos que não se encontravam apropriados à realidade. E enquanto lá, a preocupação foi em trazer maior igualdade social, 
minimizando a pobreza, aqui se pensava em exercer um maior controle sobre o pobre por meio de sua moralização ao mesmo tempo em que se impedia que o povo alcançasse a cidadania plena.

No Brasil a equipe letrada que dominava a situação política da época vivenciava um paradoxo: precisava promover a educação, para "civilizar" a nação, mas por outro lado, não queria abrir mão dos privilégios que possuía como "herança”. A contradição se encontrava no fato de educar o povo, como único meio de se alcançar o desenvolvimento do país, porém, mantendo-o sob vigilância e controle, sob a desculpa de fazer com que a ordem pública prevalecesse (RIZINI, 2007).

Nesse sentido, conforme vimos anteriormente, com o objetivo de se conseguir transformar a nação, percebeu-se que era preciso também cuidar da criança, e parte desse cuidado, consistia em oferecer educação e ajudá-la a sair da condição de exclusão em que se encontrava. Na prática, porém, no que dizia respeito à infância pobre, educar possuía o sentido de "moldar" para a submissão. Em comparação com o tempo anterior, essas novas ideias apresentaram alteração apenas em relação à forma de fazê-lo, pois a manutenção da vigilância e do controle, continuaram os mesmos. É por isso que Rizzini afirma que o país:

[...] optou pelo investimento em uma política predominantemente jurídico-assistencial de atendimento à infância, em detrimento de uma política nacional de educação de qualidade, ao acesso de todos. Tal opção implicou na dicotomização da infância: de um lado, a criança mantida sob os cuidados da família, para a qual estava reservada a cidadania; e do outro, o menor, mantido sob a tutela vigilante do Estado, objeto de leis, medidas filantrópicas, educativas/repressivas e programas assistenciais, e para o qual, (...) estava reservada a "estadania”. ${ }^{2}$ (RIZZINI, 2007, p. 29, grifos da autora)

À frente do país, ou seja, elaborando e votando as leis, estabelecendo normas e sanções, pensando e atualizando projetos para o progresso do Brasil, encontrava-se uma elite intelectual e política. Essa elite considerava-se apta a elaborar os planos de salvação do país, de construí-lo e quem sabe projetá-lo no exterior. A seus olhos, os pobres com sua aura de viciosidade não se encaixavam nesse ideal de nação, pois no pensamento da época, pobreza e degradação moral estavam sempre associadas.

Os caminhos para a mudança eram, portanto, conhecidos, passavam pelo processo de igualdade entre os indivíduos buscando proporcionar o fim da pobreza, e o acesso à educação para todos, baixando definitivamente os níveis de analfabetismo. Entretanto, conforme vimos, as elites brasileiras no poder, optaram por maquiar o problema oferecendo aos pobres um atendimento paternalista, que apenas serviu para minimizar a situação de miséria e fornecendo uma educação básica que permitiu o acesso de um maior número de trabalhadores às indústrias, atendendo também aos interesses do empresariado, por meio de uma educação voltada para o trabalho, que no início do século XX, não veio acompanhada da tão esperada e necessária democratização do ensino. 
A partir desse momento poderemos acompanhar uma crescente busca por tal democratização, porém, muito ainda teria que ser percorrido até chegarmos a sua garantia em termos legais, o que não impede que a realidade vivenciada no país ainda esteja distante da conquista da educação plena e de qualidade para todos. Atualmente, pelo menos na letra da lei toda criança maior de seis anos deve estar matriculada no Ensino Fundamental e a possibilidade de acesso à escola foi viabilizada de diversas formas pela Constituição Federal de 1988 e reforçada pela Lei de Diretrizes e Bases da Educação Nacional (Lei Federal n 9394/96). Na prática, porém, ainda deveremos nos questionar se os direitos das crianças e adolescentes à educação têm sido realmente garantidos.

Percebemos assim, que é no século XIX que, no Brasil, a infância passa a ser vista como uma questão de Estado e a escola eleita como uma das principais instituiçóes que deveriam ser responsáveis por auxiliar no cuidado dessa questão. A institucionalização de obrigatoriedade dos pais e responsáveis em dar a instruçáo elementar às crianças foi um acontecimento predominantemente político. Fazia parte do conjunto de normatizações necessárias no sentido de produzir a consciência de pertencimento nacional, com um imaginário de sociedade na qual os membros compartilham direitos e obrigações. A escola nesse sentido, se apresenta como "unidade de referência civilizatória" que ajudará a produzir novos valores e atitudes (Cf. VEIGA, 2007, p. 44).

Naquele momento, houve o reconhecimento da escola como meio de universalização da possibilidade de inserção social, passando também a se perceber a necessidade de envolvimento do Estado no sentido de prover escolas e criar condiçôes favoráveis para o acesso e permanência das crianças ali. Na prática, porém, quase um século teve que se passar para que uma educação pública, laica e gratuita pudesse ser realidade para um maior número de pessoas e apenas no final dos anos 1980 é que a legislação brasileira demonstra maior preocupação com esse tipo de Educação e que o Estado começa a efetivamente realizar algo.

A legislação produzida nos anos 1980 e 1990, e que se encontra em vigência, aponta uma preocupaçáo maior com os direitos individuais, dentre eles com os direitos da criança e do adolescente bem como, com a necessidade de se educar para a cidadania, meio considerado importante para a formação de cidadáos e de indivíduos aptos a participar de uma democracia.

A legislação, que compreende a Constituição Federal de 1988, o Estatuto da criança e do Adolescente (Lei 8069/90) e a Lei de Diretrizes a Bases da Educação (Lei 9394/96), tem sido de grande importância para a formação da democracia e da cidadania no país, porém, apesar de mais de vinte anos de promulgação da Constituição Federal, podemos dizer que no Brasil, ainda se está aprendendo a exercer a cidadania e a vivenciar o espírito de democracia.

O Estado brasileiro que no início do século XX começou a intervir nas questóes referentes à criança e ao adolescente visando coibir todo comportamento considerado desajustado, objetivando um maior controle social, passa a intervir, demonstrando agora uma preocupaçáo com os direitos das crianças e adolescentes e não apenas com a punição de atos indevidos por parte dos mesmos. 
Em termos legais os direitos parecem claros e em sua maioria realizáveis, resta, porém, ao Estado e à sociedade, o empenho em seu cumprimento.

Podemos dizer que avançamos em relação ao reconhecimento de direitos de crianças e adolescentes que em outras épocas nem mesmo eram vistos como indivíduos merecedores de atenção, porém, não podemos nos conformar com essa melhoria e devemos lutar para que muito mais ainda seja alcançado. É preciso ter como objetivo o alcance de uma situaçáo de muito mais estabilidade e segurança para a infância e a adolescência de maneira a que, os casos de maus tratos e violência contra eles, se tornem exceção e não sejam mais noticiados constantemente nos meios de comunicação.

\section{REFERÊNCIAS BIBLIOGRÁFICAS}

ARIÈS, Philippe. História social da criança e da família. Rio de Janeiro: LTC, 1981.

DEL PRIORE, Mary. Apresentação In: (org.). História das crianças no Brasil. São Paulo: Contexto, 2000 .

DEL PRIORE, Mary. O cotidiano da criança livre no Brasil entre a Colônia e o Império. In: (org.).

História das crianças no Brasil. São Paulo: Contexto, 2000.

LODOÑO, Fernando Torres. A origem do conceito Menor. In: DEL PRIORE, Mary. (org.). História da criança no Brasil. 3. ed. São Paulo: Contexto, 1995.

MARCÍLIO, Maria Luiza. História Social da Criança Abandonada. São Paulo: Hucitec, 1998.

. A lenta construçáo dos direitos da criança brasileira - Século XX. Biblioteca virtual de Direitos Humanos da Universidade de São Paulo, [sd]. Disponível em:

<http://www2.ibam.org.br/municipiodh/biblioteca\%2FArtigos/criança.pdf>..Acesso em: 21 abr. 2009.

MERISSE, Antônio. Origens das instituições de atendimento à criança pequena: o caso das creches. In:

et al. Lugares da infância: reflexôes sobre a história da criança na fábrica, creche e orfanato. São Paulo: Arte \& Ciência, 1997.

MORAES, Carmen Sylvia Vidigal. A normatização da pobreza: crianças abandonadas e crianças infratoras. Revista Brasileira de Educaçáo. Set/Out/Nov/Dez 2000, n 15. Campinas-SP/Rio de Janeiro: Autores Associados/Anped, 2000.

MOURA, Esmeralda B. Crianças operárias na recém-industrializada São Paulo. In: DEL PRIORE, Mary (org.) História das crianças no Brasil. São Paulo: Contexto, 2000.

PASSETI, Edson. Crianças carentes e políticas públicas. In: DEL PRIORE, Mary (org.) História das crianças no Brasil. São Paulo: Contexto, 2000. 
RAMOS, Fabio Pestana. A história trágico-marítima das crianças nas embarcações portuguesas do século XVI. In: DEL PRIORE, Mary (org.) História das crianças no Brasil. São Paulo: Contexto, 2000.

REZENDE, Maria José de. As desigualdades no Brasil: uma forma de violência insuperável? As reflexôes de Manoel Bonfim, Euclides da Cunha, Fernando de Azevedo e Josué de Castro. In: SCHILLING, Flávia. Direitos Humanos e Educação: outras palavras, outras práticas. São Paulo: Cortez, 2005.

RIZZINI, Irene. O século perdido - Raízes históricas das Políticas Públicas para a Infância no Brasil. 2. ed. São Paulo: Cortez, 2007.

VEIGA, Cyntia Greive. Cultura escrita: representaçôes da criança e o imaginário da infância. Brasil, século XIX. In: LOPES, A. FARIA FILHO, L. M; FERNANDES, R. Para a compreensáo histórica da infância. Belo Horizonte: Autêntica, 2007.

VENÂNCIO, Renato P. Famílias abandonadas - Assistência à criança das camadas populares no Rio de Janeiro e em Salvador - séculos XVIII e XIX. Campinas: Papirus, 1999.

. Os aprendizes da guerra. In: DEL PRIORE, Mary (org.) História das crianças no Brasil. São Paulo: Contexto, 2000. 